\title{
Brazil to boost science spend
}

"Don't you come back into my office asking for more money until 2010.” Brazilian president Luiz Inácio Lula da Silva’s playful admonishment to his science minister came after the president's announcement last week of a remarkable US\$28-billion package for science and technology over the next three years. The spending promised is equivalent to $1.5 \%$ of the country's GDP - currently, science receives about $1 \%$ of GDP.

The investment is part of a federal plan to improve academic research and to counter the lack of technological innovation in the industrial sector, which is a special cause of concern. Most researchers in Brazil are still employed in the public sector, which has helped to energize the academic community, with the number of scientific publications increasing by around $9 \%$ a year since 2000 . Now, $2 \%$ of the world's scientific publications are Brazilian - ranking it 15th in the world.

But despite this, the private sector is losing out because of an absence of qualified researchers. Brazil is responsible for just $0.1 \%$ of all the patents registered globally each $\Sigma$ year, according to a 2007 report by the Organisation for Economic Co-operation and Development. To address this, the government's new science plan includes extensive grants and tax breaks for research projects conducted by private companies. Funding for postgraduate qualifications will also continue

President Lula: science for industry.

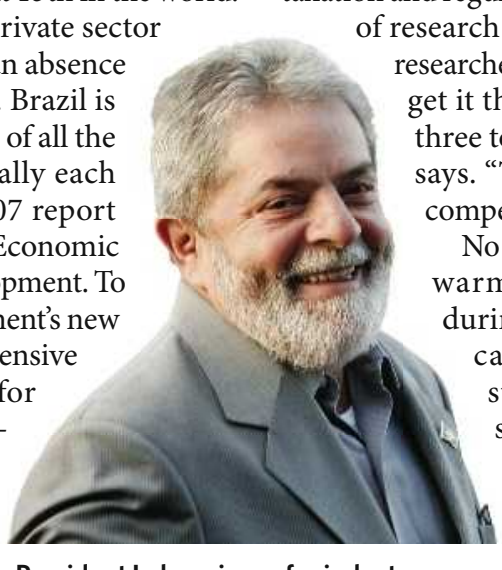
who needs a product can to six months for it," Mello s. "There's no way we can be mpetitive like that."

No surprise then that the most warmly applauded moment during Lula's speech last week came when he vowed to streamline the import of scientific instruments. On paper at least, the future of science in Brazil looks promising. João Medeiros to take the stage in Bali. Advances in aerial and satellite monitoring should help in answering the first question, and the tropical nations have developed various policy solutions to the second.

Costa Rica and Papua New Guinea led the Coalition for Rainforest Nations in a proposal to revive the question at the climate talks in Montreal in 2005. Recently, Indonesia has joined Brazil and other major countries in the 'Forestry 11' coalition, which includes 11 nations representing some $85 \%$ of the world's tropical forests, according to the Union of Concerned Scientists.

The proposals vary, but all tend to focus on verified emissions reductions, as opposed to upfront payments on projects intended to achieve certain targets. The Coalition for Rainforest Nations, for instance, proposes that deforestation be tracked on a national level, with carbon credits being sold only after a decrease in national emissions in that sector had been verified.

Although these nations have not endorsed a single idea, Boucher says, they are united in their efforts to ensure that deforestation has a clear place on the agenda for post-Kyoto deliberations.

"Deforestation is front and centre," says Steve Ruddell of Forecon, a consultancy based in New York that works on carbon markets and forestry issues. "It's still not a done deal, by any means, but I think the time is right." Jeff Tollefson

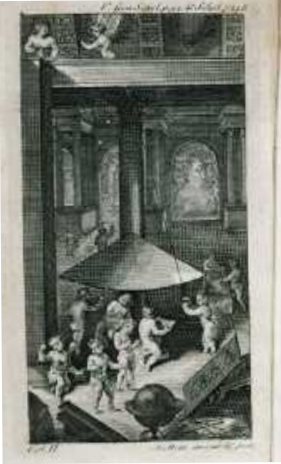

HAVE YOUR SAY

Comment on any of our news stories, online.

www.nature.com/news

\section{MATHEMATICAL}

PRI NCIP LES

Natural Philofophy.

By Sir ISAAC NE WTON Tranlated inm ENGLISII Vot

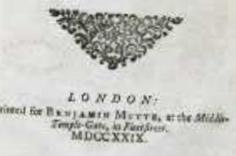

Now in Arabic...

Hundreds of science books, including classics by Isaac Newton and Stephen Hawking, will be translated into Arabic for the first time. The ambitious plan by a non-profit group in Abu Dhabi has the backing of the Crown prince and funding from the Abu Dhabi Authority for Culture and Heritage.

The project, called Kalima ("word" in Arabic), is an attempt to address the fact that, although there are more than a quarter of a billion Arabic speakers worldwide, only a few hundred books are translated into Arabic each year. The group is working with more than 20 publishers throughout the Arab world. It plans to help them acquire, translate, publish and distribute about 100 books in Arabic every year. Around a quarter of these will be science titles.

"There is a particularly large gap in the Arab library of books in the natural-science category," says Karim Nagy, the Egyptian entrepreneur and book collector who directs the project. "We have therefore purposely placed a heavier weighting on it."

One book already translated is A Briefer History of Time,

Stephen Hawking's revision of his best-seller (see above). Next year, Kalima will translate books by Niels Bohr, Werner Heisenberg, Max Planck and Richard Feynman into Arabic, and prepare Arabic versions of recent works by Roger Penrose, Steven Weinberg and Freeman Dyson. Other scientists to be translated include Stephen Jay Gould, Stephen Wolfram and James Watson. Eventually, Nagy hopes also to begin translating Arabic books into English and other languages.

Jascha Hoffman

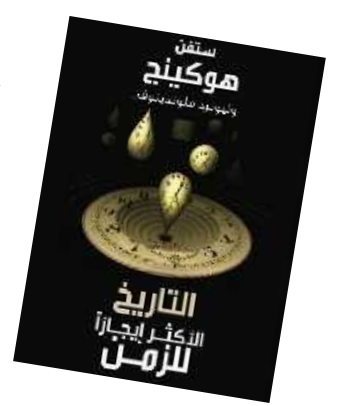

